\title{
Gamification concept for encouraging lecture attendance
}

\author{
Vinothini Kasinathan ${ }^{1}$, Aida Mustapha ${ }^{2}$, Chan Kok Fu ${ }^{3}$, Mohamad Firdaus Che Abdul Rani ${ }^{4}$, \\ Sadesh Manikam ${ }^{5}$ \\ ${ }^{1,3,4}$ School of Computing, Asia Pacific University of Technology and Innovation, Taman Teknologi Malaysia, Malaysia \\ ${ }^{2}$ Faculty of Computer Science and Information Technology, Universiti Tun Hussein Onn Malaysia, Malaysia \\ ${ }^{5}$ Advanced Informatics School (AIS), Universiti Teknologi Malaysia, Malaysia
}

\begin{tabular}{l} 
Article Info \\
\hline Article history: \\
Received Jan 9, 2019 \\
Revised May 3, 2019 \\
Accepted May 27, 2019 \\
\hline
\end{tabular}

Keywords:

Attendance system

Education

Gamification

\begin{abstract}
New generation of students has high dependence on technology and embrace social learning environments that have low barrier to access. This means inclass lectures are not popular anymore, and in fact has become a burden for them to cope. To resolve the issue of low student attendance, this paper proposes a character growth game with the concept of gamification in education that is able to track and reward student attendance called PetAttendToClass. PetAttendToClass is a client-based system developed using $\mathrm{C \#}$ and unity3D game engine. Although finding from the UAT session revealed that some users believed that attendance is the responsibility of the student, gamification is meant to turn this mundane responsibility into something motivative, interactive and interesting. It is hoped that by gamifying the class attendance, student will be motivated to attend their daily classes.
\end{abstract}

Copyright () 2019 Institute of Advanced Engineering and Science. All rights reserved.

\section{Corresponding Author:}

Vinothini Kasinathan, School of Computing,

Asia Pacific University of Technology and Innovation,

Taman Teknologi Malaysia, 57000 Kuala Lumpur, Malaysia.

Email: vinothini@apu.edu.my

\section{INTRODUCTION}

Students currently in the higher educational system have different learning take-away as compared to the earlier generations. As a digital native, this generation expects digital learning tools and platforms that are able to deliver the content on-demand basis while at the same time expecting a personal experience with the lecturers. Not only this generation has high dependence on technology, they also embrace social learning environments that have low barrier to access. This means in-class lectures are not popular anymore, and in fact has become a burden for the new generation to cope. This is a profound problem due to very small interaction between lecturer and students, weak reputation and higher gap between different authorities. Students who have less interaction with lecturer are often hard to seek for clarification or support from the lecturer to master the subject. This, in turn, will affect the understanding of the student towards the module and lack of guidance to complete the given assignments.

To resolve the issue of low student attendance, this paper proposes a character growth game with the concept of gamification in education that is able to track and reward student attendance. Character growth game known as the Tamagotchi device was released by Bandai Organization in Japan back in 1996. Tamagotchi was the first character growth game that allow player to slowly develop the growth of a creature from an egg to an adult. Basically, the idea is that students own an egg which contain any kind of creature and have to hatch it by attending classes and may request helps from lecturer to grow their owned creature. Meanwhile, the lecturer will own a goddess creature which can provide boost to students' owned creature 
and conduct an event for collect limited in-game items. The game events can be easily incorporated as inclass activities to turn the class environment into a game community that promotes interaction between the lecturer and students.

The development of an interactive character growth game will also be a suitable way to implement gamification into the class, neutralizes the tense study environment and reduces the gap between lecturer and students. Interaction can be started through the program and creating common topics to discuss other than tough and complex knowledge about the module. The proposed system will also consist of general game components like in-game items, in-game currency and leaderboard. While games can be an entertainment, it can provide new ways to learn. Games is a program that entertaining, interactive and able attract lot of players even it is not commercial, therefore it can be a great path for convergence, which is today's trend. Games are also able to create a social network with any level of people and as discussion start, new topics can be created.

According to [1], gamification is a technology that apply game elements into non-game settings, which is a popular trend that turns non-game system into an entertaining gamified system. Moreover, the objective of this trend is to promote commercial or educational contexts, increase the user's motivation and engagement with playful contents [2]. The research also noted that gamification can potentially augment user experience with game elements into commercial, educational contexts. These make non-game applications become playful and engaging, attracting more customers or users to engage. As gamification gained a great amount of attention in past few years, gamification blurred the boundary between games and non-game system. Even though gamification on the current trending method to increase the motivation and engagement of users, it can also be conceptualized as [3, 4]. In their paper [9] explain the concept of gamification boost the students engagement is class activities.

Gamification concepts can be decomposed into three main parts: motivational affordance, psychological outcomes and behavioral outcomes [3]. These are the goal which defining the gamification content in an application or system. Motivational Affordance are the features which allow user to visualize the milestones and achievement, point gain feature, leaderboard, and levels. This is one of the game elements which attracting and keeping user to play and use the system, creating opportunity to achieve something. Relating to the proposed system, in-game character growth will be reflected by the student personal attendance value. Motivating student to attend class and retrieve attendance from lecturer, incrementing the growth of the in-game character. With the affordance in game elements, psychological and behavioral outcomes will show the effects of gamification. The change in motivation, attitude and enjoyment to engage the system and increases the user involvement with gamified features [10-12].

Game elements are the main component that gamify the non-game system, whereby common game elements as following: Avatars, Ranks, Levels, Storyline, and Rules [2]. These game elements help the application to achieve motivational affordance in gamification concept. Although, these elements be called as the "characteristic" of games, but can also be used in other entertainment application and not specify to relative game genre. Design of a gamified system, also require game mechanisms and strategies [13-16]. Game elements, mechanisms and strategies are designed to motivate the user and increase the user's engagement based on intrinsic motivation theory. Intrinsic motivation is the passion that keep the person motivated to perform the task or work, also typically linked to game [17-20]. In gamification, motivational affordance can potentially draw out the intrinsic motivation from user which also can maintain the user's passion on using the system [1]. To maintain the intrinsic motivation of user, some game features will help on keeping the passion of user, example: leaderboard, score, accumulate in-game currency and level, which created a competitive environment between users, as user like challenges [21].

Besides increase motivation and engagement of users, game also created for relationship-building. Game can create a community for users to share and discuss on gameplay strategies and experiences, which influencing our social network, connecting users through the system [5]. This advantage of gamification enables the proposed system to achieve the objectives to build better reputation between students and lecturer. In conclusions, gamification should start with game elements which make the non-game system become a playful and fun system. Next, aim to promote or maintain the intrinsic user motivation by implementing motivational affordance like leaderboard and competitive rules.

The literature has shown sufficient examples that gamification can greatly improve student performance and keep student motivation in classroom. Students nowadays refused to be passive learners and expects to be fully engaged in the learning process themselves [22, 23]. Passive learning and active Learning are the common method which widely been used in vary degree of education to improve the teaching practice and compatible to the new era of education [6] described the difference between passive and active learning, where lecturing, one direction learning and watching video considered as passive learning and discussion session, brainstorming, role-playing and group work are example for active learning which has higher 
engagement and interaction than passive learning. They also stated that active learning activities can lead to a higher level of critical thinking, uncover the potential of learners.

Other than passive and active learning techniques, there are deeper knowledge in student learning style which used to understand learner preferred learning method. Whereas suitable learning style can ensure the appropriateness of intervention and risen the potential for success in understanding the knowledge. Learning style can be assessed by various of framework such as the VARK@ framework [6] that measures four perceptual preferences; visual (V), aural (A), read/write (R) and kinesthetic (K). Using these perceptual preferences to categorize types of learner, visual learner prefer graphical information like patterns, graphs and maps; aural, auditory learner prefer verbal information, like to receive knowledge through verbal exchange or a discussion; read/write learner would like to read and write the knowledge in black and white, more likely to take notes and keep the notes as study supplement; kinesthetic learners are individuals who practical session, like to apply the knowledge and understand the knowledge from experience [23, 25].

Generation today strive for active learning, which can result in improved knowledge retention and provide deeper understanding on the study material by focusing on learner's needs which similar to customer's satisfaction in business today. Besides the word passive and active in learning style, [7] stated that passive and active learning can be rephrased into surface and deep. Surface learning is learning to avoid failure and rote memorizing where might be blindly memorize the material given for exam. On the other hand, deep learning involved intrinsic motivation where student learn for its pleasure toward the module or subject. Deep learning allowing student to analyze the learnt knowledge and apply their creativity. Other framework includes the behavioral-based cognitive engagement activities that are categorized into four modes: Interactive, Constructive, Active and Passive (ICAP) [8]. This approach promotes constructive learning and generating new finding from received knowledge via interactive learning, debating or discussing on the subject in a group or asking questions on confusion and seek for the answers.

This paper presents the idea of using gamification concept for encouraging lecture attendance by building a prototype to simulate attendance system database for a group of students. The remainder of this paper is organized as follows. Section 2 presents the proposed PetAttendToClass system. Section 3 presents the results for User Acceptance Testing (UAT), and finally Section 4 concludes with some future plans.

\section{MATERIALS AND METHODS}

This paper proposes an attendance rewarding system called PetAttendToClass. This system simulates the increment on student attendance on a module and the milestone for the accumulated attendance. This system involves two clients, which are students who enrolled in a particular course, and lecturer who give marks for the lecture attendance. For Client 1, students are allowed to access their application which having a virtual pet and view their current attendance value. The system will require student to login for validate the user profile. In PetAttendToClass, the system consist of login feature and rewarding feature as a milestone is reached at certain accumulated attendance value.

The system emphasized on the gamification concept, therefore the prototype is implementation focused on client 1 where gamification concepts are applied. Client 2 will be a simulator to manipulate the student attendance value in the database. The system has a simple database with one table to store Student Identification (TP), Name and Attendance Value. Client 1 is also able to retrieve the latest data from the database real-time as Client 2 modified the data. For example, Client 2, lecturer incremented a student attendance value; Client 1, student is using the application in the moment, the value will be updated as database been updated. This is to perform a real-time or near real-time services.

Figure 1 shows the login and warning screen for PetAttendToClass system. The default starting scene for student to login and validate their account in the database. For invalid user, warning message will show to warn user when invalid TP number and password are entered. The warning notification can be removed by click on the notification and allow user to try again.

Figure 2 shows the main screen for PetAttendToClass system. As above in the figure, the system has an in-game character which can be interacted with by the control on keyboard. The core feature of the system is the accumulated attendance and milestone reward. The star button on the progress bar is a reward button, which will show only when milestones are reached. The milestone for each accumulated attendance is $25 \%$, $50 \%, 75 \%$ and $100 \%$ for full attendance, which is 32 . The mushroom-like tree on the left is the collected reward for the first milestone. 

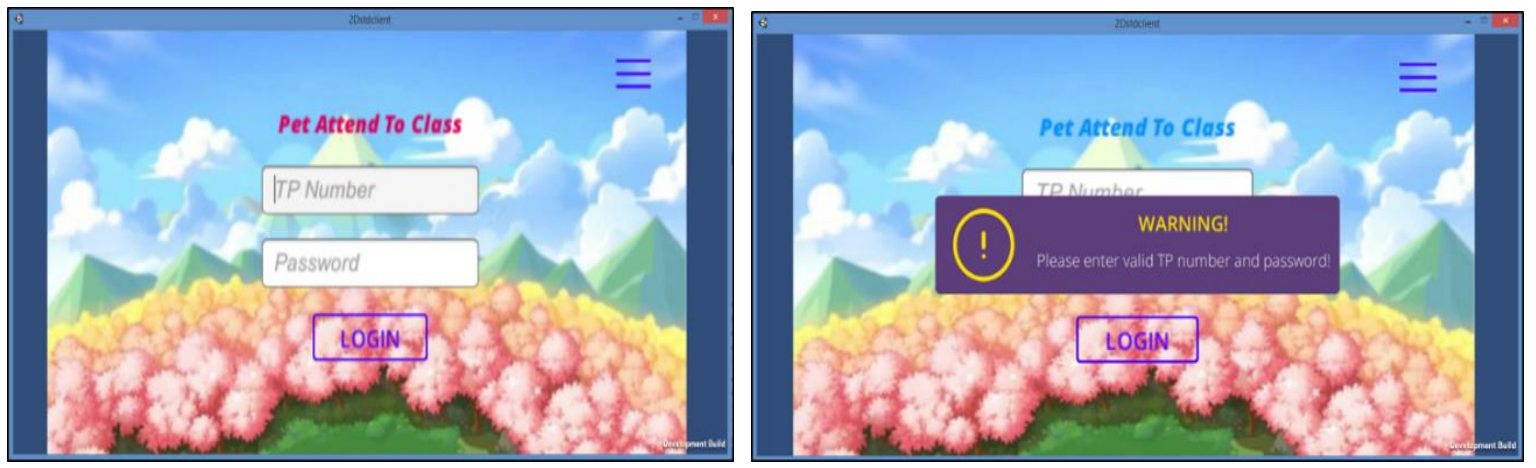

Figure 1. Login and warning screen for PetAttendToClass

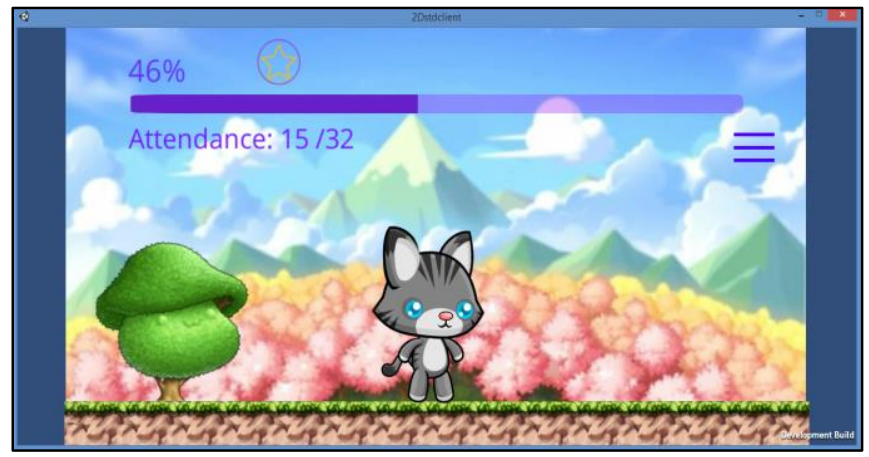

Figure 2. Main scene of PetAttendToClass

When the a milestone is reached, the next star button will be displayed. There are difference between the two displayed buttons, the faded (disabled) button means the reward has been collected; the second button which is filled shows the reward that has not been collected. Figure 3 shows the milestone achievement in the main scene.

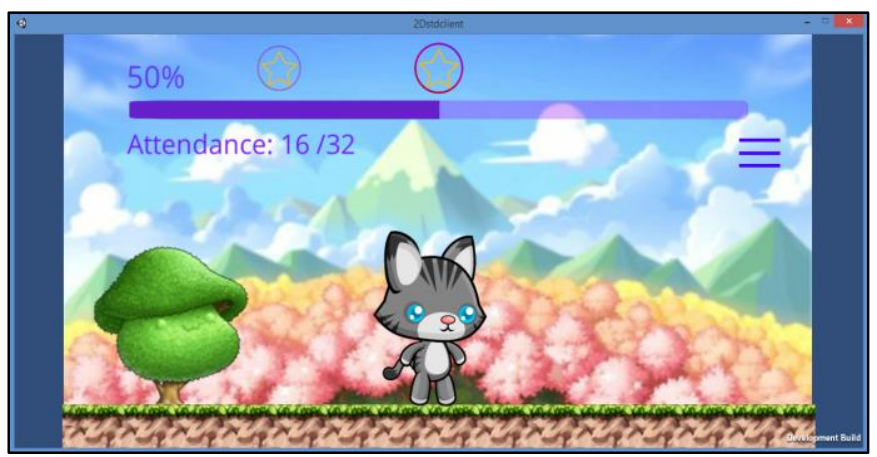

Figure 3. Second milestone reached (main scene)

User can collect the reward by clicking on the button, a chest will drop from the sky, the upper boundary of the scene. As reward button been clicked, the button will be disabled and changed to different colour. By clicking on the chest, the second reward item will be displayed which shows that the user has reached a milestone. Figure 4 shows the reward collection mechanism in PetAttendToClass system. In this figure, the second reward for the second milestone is the balloons. Likewise, when the next milestone reached, the next reward button will appear and reward can be collected. 

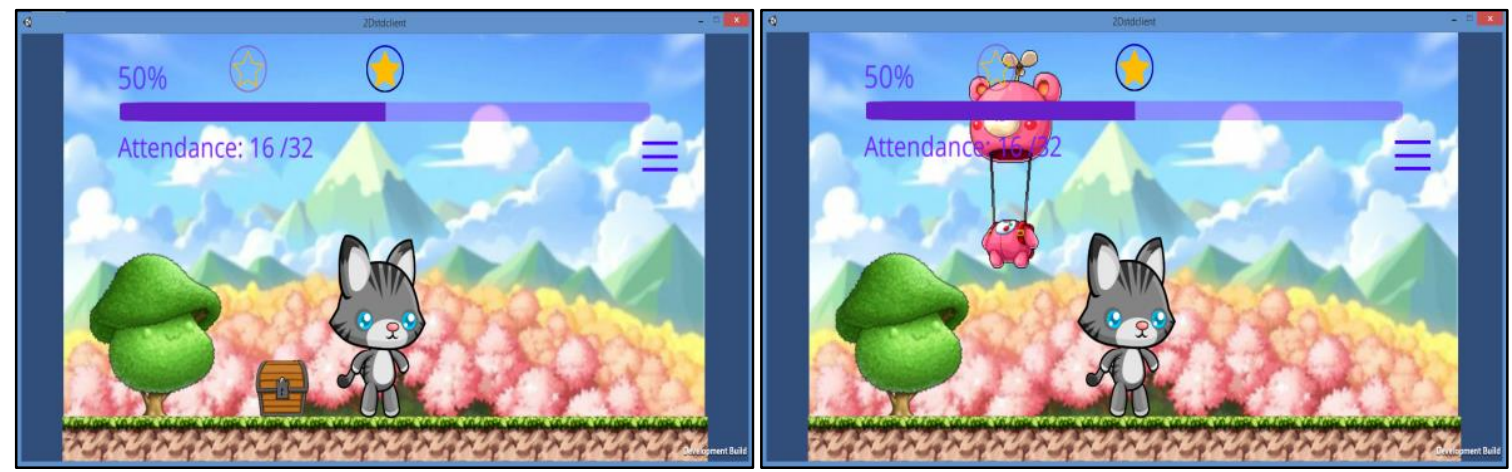

Figure 4. Collect rewards from the chest

Finally, Figure 5 shows the end scene where all the rewards have been collected. This indicated that the student has full attendance and achieved every milestone, as well as have redeemed all the rewards. The exit button allow user to exit the application and save the current state to the database.

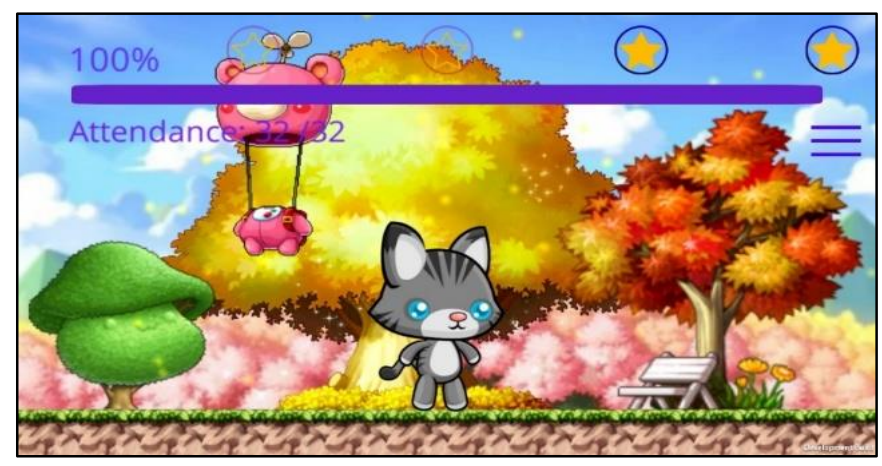

Figure 5. End game scene

PetAttendToClass system was implemented with unity3D game engine for gamification features like animation and particle effects. As for Client 2, lecturers are able to mark attendance for students. The client is developed using C\# in window form. Note that all the sprites and images used in the system are all downloaded from open-source and for non-commercial purposes only. Also, there are free unity asset been used, like buttons and other user interface components.

The major challenge in developing this game was the design of sprites. In PetAttendToClass system, all the sprites were downloaded from open sources and used unity free assets. During development and deployment, Microsoft SQL were not compatible with the connection strings used in the unity scripting, where the connection strings cannot be used with windows authentication connection, the solution was to used is SQL authentication with username and password with local IP address. There was a drawback with SQL authentication connection, as the database reimported into another device, the username and password would not be same as the original device where each local server has own SQL authentication username and password. Some features are simple, but some are complicated like scripting on the unity game object animation.

\section{RESULTS AND ANALYSIS}

PetAttendToClass was evaluated by conducting a User Acceptance Testing (UAT) to assess the acceptance of the proof of concept among the target users. Questionnaire was distributed to 30 participants to gather feedback and suggestion on features. The questions focused on how user feels about the concept of gamification for class attendance, reasons why the users like the concepts, and whether the users will adopt to the system if they are implemented. 
Figure 6 to Figure 10 show the findings. From the statistical graphs and chart, majority of the users are agreed on the gamification concept where emerge gamification into attendance system can motivate student to attend classes. Furthermore, there are few suggestion and feedback from users where mostly emphasized on the system gameplay, computer graphics and more interaction with the virtual pet like feeding. Other suggestions to enhance the system include improving the design in graphic illustrations, characteristic on the virtual pet, more scripting on animations and effects. From the user acceptance testing, the system concept is resulted in positive where most of the users accept the idea and concept to implement gamification features into attendance system.

\section{Do you like the concept of gamification into attendance system?}
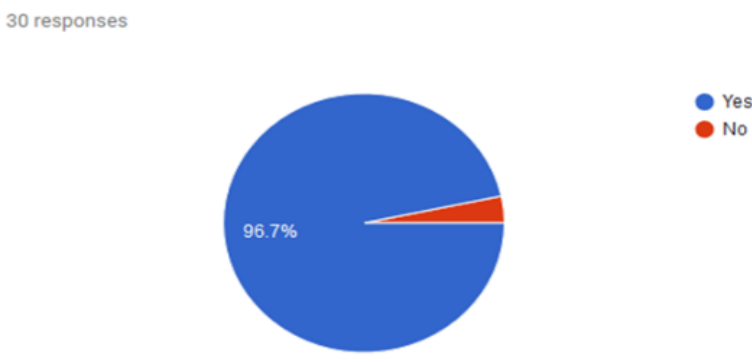

Figure 6. Most of the user like the concept of gamification for their class attendance

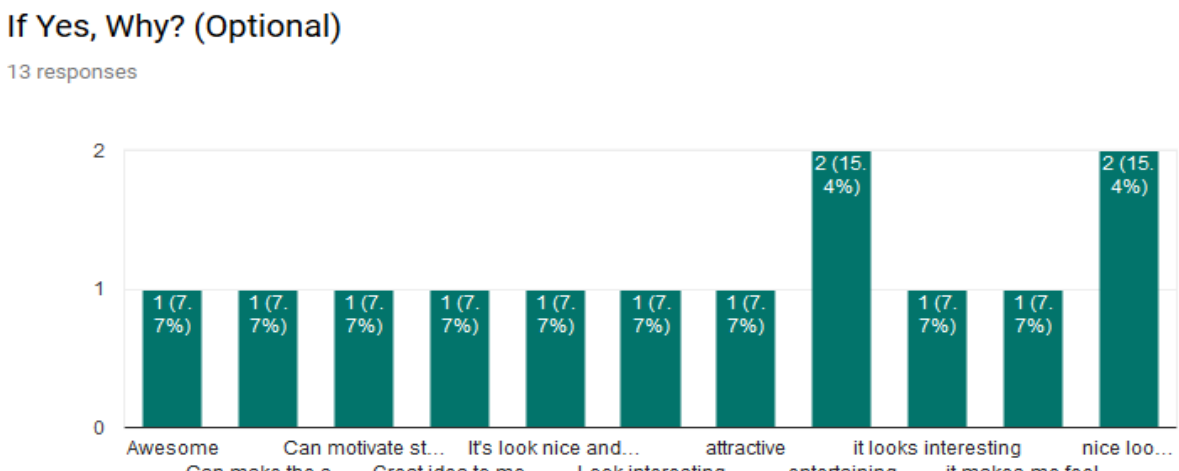

Can make the s... Great idea to mo... Look interesting it makes me feel.

Figure 7. Most popular reasons for choosing the gamification concept is because the game is entertaining

2. If this system been released into and applied into current attendance system, would you like to use it? (Do you enjoy using this gamified system?)

30 responses

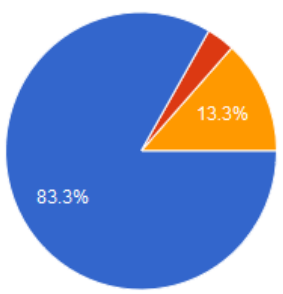

Y Yes

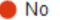

Maybe

Figure $8.83 .3 \%$ users agreed for the gamification concept to be implemented in lectures 
To prove that most of the people play mobile games, mobile games is the trend for now. This finding show mobile game is attractive and most of the people have downloaded. Constructing the proposed system into a mobile game might greatly encourage users to download and use it Figure 9 shows the user responses for this question Why component of game attracts the user to install the mobile application on their phone.

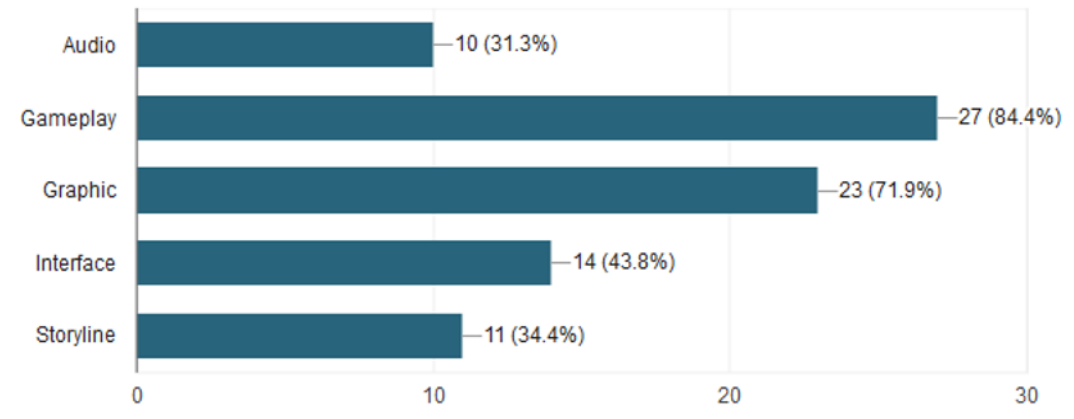

Figure 9. Number of users willing to install the application on their phone and the reason

This finding shows the core component to be prioritized on proposed system, character growth game, which a type of role playing game (RPG). The gameplay is the most attractive part of mobile game which users highly concerned. Followed by graphical and user interface, which related to the front-end implementation. The last question as summarized in Figure 10 concluded users like the concept of gamification and agreed that PetAttendToClass provides a more fun way for attendance system and time saving for huge auditorium classes.

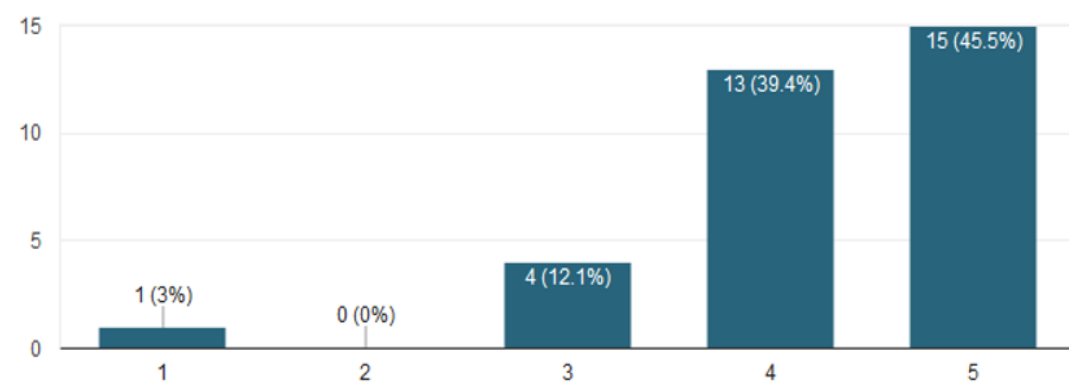

Figure 10. Percentage of students enjoying PetAttendToClass

To find the feasibility of the proposed project, most of the responses is positive. Gamification can be accepted to be implemented and emerged into the attendance marking system.

\section{CONCLUSIONS}

The paper introduced a gamification concept to be applied in a mundane class attendance system through a prototype called PetAttendToClass. It is designed to be a character growth game with the concept of gamification in education that allows the system to track and reward student attendance. Although finding from the UAT session revealed that some users believed that attendance is the responsibility of the student, gamification is meant to turn this mundane responsibility into something motivate, interactive and interesting. For further enhancement on the system, it is proposed to develop gamification on both clients with multiple connection to server for marking attendance with the least time taken as suggested during the UAT. It is hoped that by gamifying the class attendance, student will be motivated to attend their daily classes. Future enhancement should include characters that students like according to their level of study. Another add on students is the reverse of the system, where they give points or rewards to their lecturers after each class on improving the class to more exciting environment for study. 


\section{ACKNOWLEDGEMENTS}

This project is funded by the Asia Pacific University of Technology and Innovation. The authors would like to thank Chan Kok Fu for the development contribution for this project.

\section{REFERENCES}

[1] M. D. Hanus, J. Fox, "Assessing the effects of gamification in the classroom: A longitudinal study on intrinsic motivation, social comparison, satisfaction, effort, and academic performance," Computers \& Education, vol. 1, no. 80, pp. 152-61, 2015.

[2] M. S. Kuo and T. Y. Chuang, "How gamification motivates visits and engagement for online academic dissemination-An empirical study," Computers in Human Behavior, vol. 1, no. 55, pp. 16-27, 2016.

[3] J. Hamari, "Do badges increase user activity? A field experiment on the effects of gamification," Computers in human behavior, no. 71, pp. 469-78, 2017.

[4] J. Hamari, J. Koivisto, H. Sarsa, "Does gamification work? A literature review of empirical studies on gamification," 47th IEEE Hawaii International Conference on System Sciences (HICSS), pp. 3025-3034, 2014.

[5] K. Seaborn and D. I. Fels, "Gamification in theory and action: A survey," International Journal of HumanComputer Studies, vol. 74, pp. 14-31, 2015.

[6] K. Lee, H. Schull, P. Ward-Smith, "Active versus passive learning: perceptions of undergraduate nursing students," Journal of Nursing Education and Practice, vol. 6, no. 9, pp. 63, 2016.

[7] A. M. Duarte, B. Cabrito, A. I. Figueira, J. A. Monge, "Teaching practices for passive and active learning in rural and urban elementary teachers," Sisyphus-Journal of Education, vol. 3, no. 2, pp. 134-54, 2015.

[8] M. T. Chi and R. Wylie, "The ICAP framework: Linking cognitive engagement to active learning outcomes," Educational Psychologist, vol. 49, no. 4, pp. 219-43, 2014.

[9] Kasinathan V, Mustapha A, Fauzi R, Rani MF. "Questionify: Gamification in Education”. International Journal of Integrated Engineering. 2018 Nov 25;10(6).

[10] Hamari J, Koivisto J, Parvinen P. "Introduction to the Minitrack on Gamification". InProceedings of the 52nd Hawaii International Conference on System Sciences 2019 Jan 8.

[11] Majuri J, Koivisto J, Hamari J. "Gamification of education and learning: A review of empirical literature." InProceedings of the 2nd International GamiFIN Conference, GamiFIN 2018 2018. CEUR-WS.

[12] Schöbel S, Janson A, Hopp JC, Leimeister JM. "Gamification of Online Training and its Relation to Engagement and Problem-solving Outcomes".

[13] Rapp A, Hopfgartner F, Hamari J, Linehan C, Cena F. "Strengthening gamification studies: Current trends and future opportunities of gamification research".

[14] Johansen JN, Dintenfass K, inventors; Bank of America Corp, assignee. "Real world gamification using augmented reality user devices". United States patent application US 10/210,767. 2019 Feb 19.

[15] Kim S, Song K, Lockee B, Burton J. "What is gamification in learning and education?". InGamification in learning and education 2018 (pp. 25-38). Springer, Cham.

[16] White M, Shellenbarger T. "Gamification of Nursing Education With Digital Badges." Nurse educator. 2018 Mar $1 ; 43(2): 78-82$.

[17] Kim S, Song K, Lockee B, Burton J. "Gamification Cases in Education". InGamification in Learning and Education 2018 (pp. 117-123). Springer, Cham.

[18] Taspinar B, Schmidt W, Schuhbauer H. "Gamification in education: a board game approach to knowledge acquisition”. Procedia Computer Science. 2016 Jan 1;99:101-16.

[19] Dicheva D, Dichev C. "Gamification in Education: Where Are We in 2015?. InE-Learn: World Conference on ELearning in Corporate, Government, Healthcare, and Higher Education" 2015 Oct 19 (pp. 1445-1454). Association for the Advancement of Computing in Education (AACE).

[20] Nicholson S. "A recipe for meaningful gamification. InGamification in education and business" 2015 (pp. 1-20). Springer, Cham.

[21] Kim B. . "Gamification in Education and Libraries. Library Technology Reports." 2015 Mar 25;51(2):20-8

[22] Nicholson S. "A recipe for meaningful gamification. InGamification in education and business" 2015 (pp. 1-20). Springer, Cham.

[23] Martí-Parreño J, Méndez-Ibáñez E, Alonso-Arroyo A. "The use of gamification in education: a bibliometric and text mining analysis". Journal of Computer Assisted Learning. 2016 Dec;32(6):663-76.

[24] Huang WH, Soman D. Gamification of education. Research Report Series: "Behavioural Economics in Action, Rotman School of Management " University of Toronto. 2013 Dec 10.

[25] de Sousa Borges S, Durelli VH, Reis HM, Isotani S. "A systematic mapping on gamification applied to education." InProceedings of the 29th annual ACM symposium on applied computing 2014 Mar 24 (pp. 216-222). ACM. 


\section{BIOGRAPHIES OF AUTHORS}

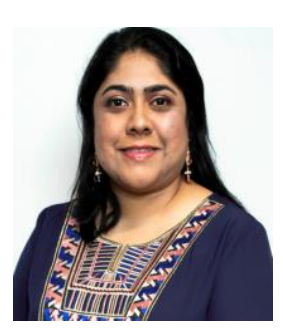

Vinothini Kasinathan is a currently as Senior Lecturer at Asia Pacific University of Technology and Innovation (APU) Malaysia. She obtained her Master in Software Engineering- Real Time System from UTM as the Dean's Merit award. She has been in the academic industry for the last 18 years. Presently pursuing her Phd in Computing. Her research interest includes educational technology, text mining, presentation mining and other areas.

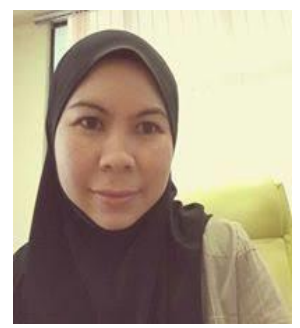

Aida Mustapha received the B.Sc. degree in Computer Science from Michigan Technological University and the M.IT degree in Computer Science from UKM, Malaysia in 1998 and 2004, respectively. She received her Ph.D. in Artificial Intelligence focusing on dialogue systems. She is currently an active researcher in the area of Computational Linguistics, Soft Computing, Data Mining, and Agent-based Systems.

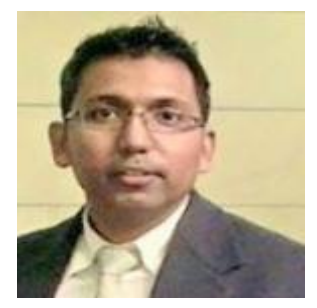

Sadesh Manikam has received the Bachelors and Masters in Real Time Software Engineering from Universiti Teknologi Malaysia (UTM), and presently pursuing his Ph.D in UTM. His research interest are in the areas of interest Bussiness Intelligence, Maturity Model, Data Governance, Data Mining, and Data Visualization and Insights.

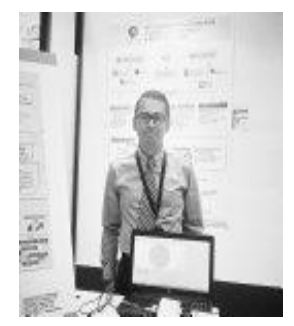

Mohamad Firdaus Che Abdul Rani is a lecturer at Asia Pacific University of Technology and Innovation (APU), Malaysia. His research interest includes Semantic Web, Web Accessibility and Knowledge Management. 